\title{
EVOLUTION OF DSt AND AURORAL INDICES DURING SOME SEVERE GEOMAGNETIC STORMS
}

\author{
Rajaram Purushottam Kane \\ Recebido em 24 julho, 2008 / Aceito em 27 abril, 2009 \\ Received on July 24, 2008 / Accepted on April 27, 2009
}

\begin{abstract}
The evolutions of the geomagnetic Dst and auroral indices AU, AL, AE were examined in relation to interplanetary parameters for thirteen severe storms (Dst change exceeding $250 \mathrm{nT}$ ) during 1980-2003. Dst changes occurred every time Bz component of interplanetary magnetic field B turned negative. Among the auroral indices, changes in $\mathrm{AU}$ (representing an eastward auroral electrojet) were generally much smaller than changes in AL (representing a westward auroral electrojet), and both started increasing almost simultaneously with increases of interplanetary magnetic field B, even though its Bz component may not have turned negative. Hence $\mathrm{AU}$ and AL changes may precede Dst changes by a few hours and could have a prediction potential. AU and AL changes were not correlated well with each other; their inter-correlation was almost zero. Whenever Bz was negative, AL indices were invariably high, but the reverse was not true. Large AL changes could occur even when Bz was not negative (or even when positive). AL values showed many peaks during the storm and these were not invariably related to Bz changes. Successive AL peaks had separations in a wide range of 40-160 minutes. Spectral analysis of hourly values showed frequent periodicities around 2-4 hours, 6 hours, and 8-9 hours.
\end{abstract}

Keywords: geomagnetic Dst, auroral indices, geomagnetic disturbances.

RESUMO. As evoluções dos índices Dst geomagnético e AU, AL e AE da aurora foram investigadas em relação aos parâmetros interplanetários de treze tempestades (com índices Dst maiores que 250 nT), no período entre 1980 e 2003. As mudanças no índice Dst ocorreram toda vez que a componente Bz do campo B magnético interplanetário se tornou negativa. Entre os índices da aurora, as mudanças do índice AU (representando o eletrojato da aurora em direção ao leste) geralmente foram bem menores do que as do AL (representando o eletrojato da aurora para oeste). Ambos iniciaram um incremento quase que simultaneamente com o aumento do campo B magnético interplanetário, muito embora não tendo, às vezes, a componente Bz se tornado negativa. Portanto, as mudanças observadas em AU e AL podem preceder as da Dst por algumas horas e com isso têm o potencial de previsão de mudança. As mudanças em AU e AL não se comportaram em paralelo e as suas inter-correlações foram quase nulas. Quando Bz se tornava negativa, invariavelmente AL era alto, porém o reverso não se realizava. Grandes mudanças em AL poderiam ocorrer mesmo quando Bz não fosse negativa (ou mesmo positiva). Valores de AL apresentaram muitos picos durante as tempestades e invariavelmente estes não se relacionaram às mudanças de Bz. Picos sucessivos de AL mostraram separações em largas faixas, entre 40 e 160 minutos. Análise espectral de valores horários mostraram freqüentes periodicidades ao redor de 2-4 horas, 6 horas e 8-9 horas.

Palavras-chave: Dst geomagnético, índices aurorais, tempestades geomagnéticas. 


\section{INTRODUCTION}

Biermann (1951, and further papers) proposed that the pointing of comet tails always away from the Sun implies material flying out of the Sun on a continuous basis. To explore this possibility, Parker (1958) formulated his theory of solar wind at the University of Chicago (Hufbauer, 1991). Further, Parker (1959) and Gold (1959) examined its implications for the stretching (extension) of solar magnetic field into the interplanetary space during quiet and enhanced solar activity. Soon after, satellite observations confirmed many of those implications, and interplanetary structures with abnormal values of plasma parameters were found to occur frequently, notably after solar flares. It was observed that geomagnetic storms occurred when the Earth was engulfed by the interplanetary abnormal structures (blobs, clouds, whatever), provided these structures had a substantial component of a southward pointing magnetic field component Bz. An explanation for the role of this negative Bz was given by Dungey (1961) as follows. If the interplanetary magnetic fields are directed opposite to the Earth's field, there is magnetic erosion on the dayside magnetosphere by magnetic reconnection and magnetic field accumulates in the night-side magnetotail region. The magnetic reconnection in the tail leads to plasma injection towards the Earth in the night-side. Low energy particles precipitate in the high latitudes and cause aurora, while high energy protons drift to the west and electrons to the east, forming a "ring current" centered near the equator around the Earth, which causes a reduction in geomagnetic field (storm time disturbance field Dst).

Geomagnetic activity is represented by several indices. The hourly Dst index (Sugiura, 1964) is obtained from the superposition of data from magnetometer stations near the equator but not so close that the E-region equatorial electrojet dominates the magnetic perturbations seen on the ground. The stations are roughly $120^{\circ}$ apart in longitude, so that superposed data at the same UT has no local-time effects. AE index is an auroral electrojet index obtained from a number (usually greater than 10) of stations distributed in local time in the latitude region that is typical of the northern hemisphere auroral zone (Davis \& Sugiura, 1966). For each of the stations, the north-south magnetic perturbation $\mathrm{H}$ is recorded as a function of universal time. A superposition of these data from all the stations enables a lower bound or maximum negative excursion of the $\mathrm{H}$ component to be determined; this is called the AL index. Similarly, an upper bound or maximum positive excursion in $\mathrm{H}$ is determined; this is called the $\mathrm{AU}$ index. The difference between these two indices, AU-AL, is called the AE index.
Strong geomagnetic storms are known to have damaging effects at high latitudes (see discussion in Kane, 2005), communication systems including those in airplanes can go haywire and power grids can go down. The most outstanding example is of the March 13, 1989 event when the Hydro-Quebec (Canada) power grid went down for more than 9 hours, and the eastern U.S. seaboard power grid was almost put down (Allen et al., 1989; Tsurutani et al., 2003). It is reported that Kp exceeding 8 is already at a dangerous level. The transition of $\mathrm{Kp}$ from 8 to 9 corresponds approximately to negative Dst exceeding $250 \mathrm{nT}$ (Kane, 2005). Such severe Dst storms seem to occur a few hours later than the start of the increases in auroral indices. Beland (2004) mentions that for Hydro-Quebec (HQ) in the province of Quebec in Canada, there are now two measurement systems (one primary and one backup) monitoring ground induced current (GIC) effects on the grid in real time. To be informed in advance of a probable GIC occurrence, $\mathrm{HQ}$ now relies on a specialized organization providing geomagnetic activity alert and forecast. Following an alert or the detection of GIC effects on the network exceeding a minimal threshold, special operation rules become in effect for ensuring maximum stability and safety margin. Also, series capacitors are introduced on several $735 \mathrm{kV}$ lines, which increase network stability and also block GIC circulation. Other installations might be using other methods. In some cases, operations are stopped (if possible) until the storm continues.

In the present communication, we propose to examine the evolutions of Dst, $A U, A L, A E$ in a rough qualitative way to check whether their behaviors are grossly different from each other, during a few selected severe geomagnetic storms (maximum Dst depression exceeding $250 \mathrm{nT}$ ). Comparison is also made with interplanetary data.

\section{DATA}

Interplanetary data and values of Dst index were obtained from NOAA websites (SPIDR etc.). Data for the auroral indices were obtained from WDC for Geomagnetism, Kyoto website http://swdcwww.kugi.kyoto-u.ac.jp/wdc/Sec3.html. The earlier interplanetary data obtained from satellites going round the Earth were found to be of a rather poor quality. In some major storms, the instruments often failed or got saturated, giving only lower limits for the data values. On August 25, 1997, ACE (Advance Composition Explorer) was successfully launched from Cape Canaveral Air Station by a Delta II rocket. The ACE observatory, a spinning spacecraft (5 rpm), orbits around the Sun-Earth L1 libration point at $240 \mathrm{Re}$ (Earth radii) sunward of the Earth. The data 


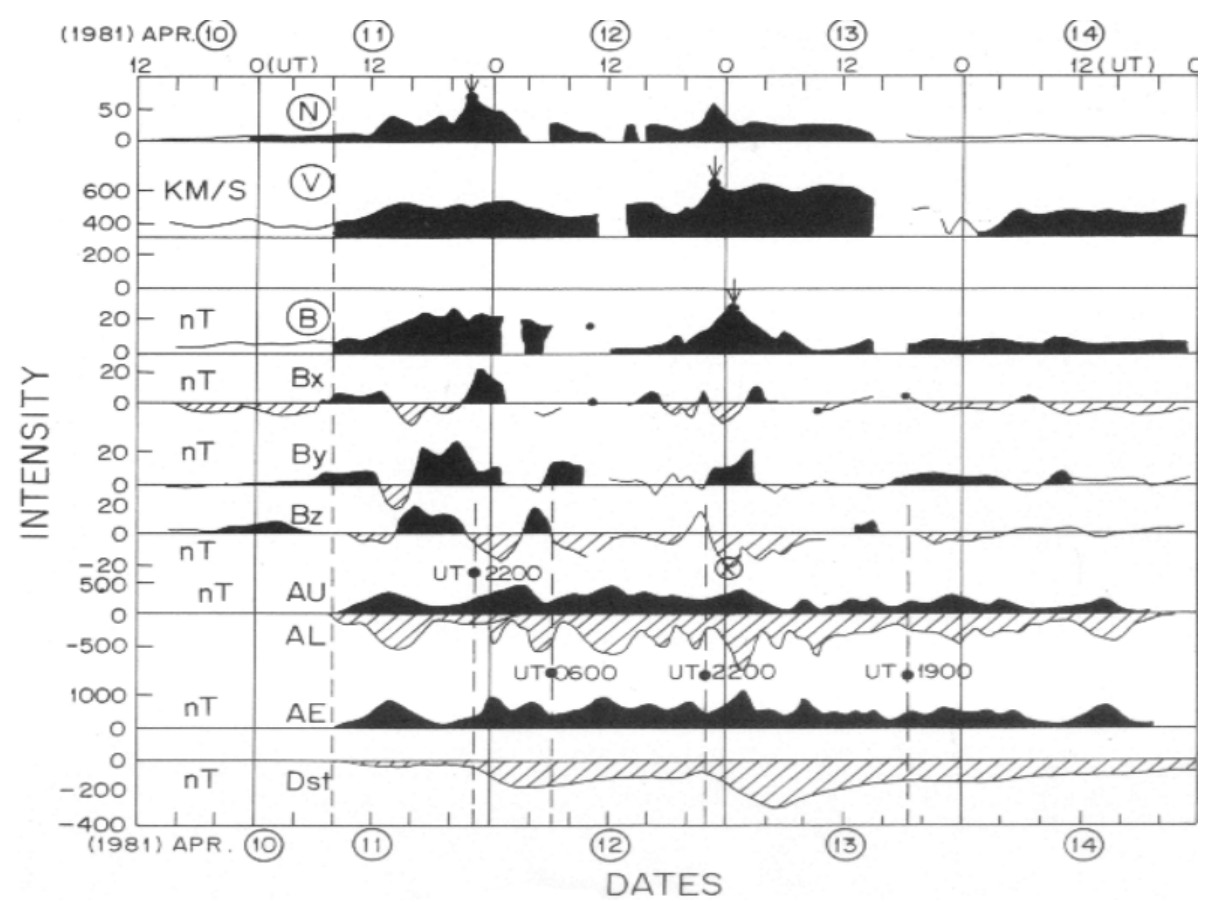

Figure 1 - Plots of hourly values of interplanetary parameters: number density $\mathrm{N}$, solar wind speed $\mathrm{V}$, magnetic field $\mathrm{B}$ and its components Bx, By, Bz, and geomagnetic indices: AU, AL, AE, Dst, during Apr. 10-14, 1981. The full vertical lines mark the 0000 UT of the dates. The storm commenced at about 0800 UT of April 11 (marked by the vertical line). Positive values are painted black and negative values are shown hatched.

from this satellite are expected to be of a better quality, but during the severe storm of October 28-29, 2003 (Halloween event), some instruments seem to have failed (Skoug et al., 2004).

\section{PLOTS FOR APRIL 10-14, 1981}

Figure 1 shows the plots of hourly values during Apr. 10-14, 1981. The full vertical lines mark the 0000 UT of the dates. The storm commenced at about 0800 UT of April 11 (marked by the vertical line) when interplanetary number density N, solar wind speed V and total magnetic field $B$ started rising. Positive values are painted black and negative values are shown hatched. The southward Bz component was only a few $n T$ negative, but the AU, AL, AE indices also increased at about the same time. In contrast, the Dst index had a very small negative value (few $\mathrm{nT}$ ) and started increasing only at about 2200 UT, almost 14 hours later, when Bz had a large negative value (about $-20 \mathrm{nT}$, marked by a vertical dashed line). Thus, Dst seems to need a threshold negative Bz value exceeding $\sim 5 \mathrm{nT}$ (Gonzalez et al., 1994) for a substantial Dst change (exceeding $50 \mathrm{nT}$ ). However, this also indicates the possibility that in some Dst storms, the auroral indices may serve as precursors, with several hours of antecedence.
The Dst index had a main phase of about 4 hours, followed by a gradual recovery, which would have taken several tens of hours but for the fact that at UT about 0600 of April 12 (marked by a vertical dashed line), there was a negative Bz excursion of about $-15 \mathrm{nT}$, which slowed the Dst recovery but did not show any abrupt change in Dst, and then another negative Bz excursion of about $-25 \mathrm{nT}$ at about $2200 \mathrm{UT}$ of April 12, which resulted into a fresh decrease in Dst (marked by a vertical dashed line) and a highest maximum Dst value of $-311 \mathrm{nT}$. There was another small negative excursion of Bz (-8 nT) at about $1900 \mathrm{UT}$ on April 13 (marked by a vertical dashed line) which only slowed down the Dst recovery. Thus, two large negative Bz excursions resulted in large abrupt Dst changes while three small negative Bz changes caused only small perturbations in Dst. This was an unusual event where negative Bz occurred so often (5 or more times in three days). As will be seen in some other events, Bz changes are confined to a small interval of a few hours (tens of minutes to several hours).

The AU (positive, eastward auroral electrojet) and AL (negative, westward auroral electrojet) values showed large deviations when $\mathrm{Bz}$ values turned negative, but the auroral indices show changes even when $\mathrm{Bz}$ is not negative, as will be seen later in other events. 
Table 1 shows the inter-correlations of interplanetary $\mathrm{N}, \mathrm{V}, \mathrm{B}$, $B z$, auroral $A U, A L, A E$, and Dst, using 96 hourly values of $A p r$. $11-14,1981$. As can be seen, most of the correlations are less than 0.45 , indicating generally poor relationships. Correlations exceeding 0.45 are:

(a) N with $\mathrm{V}(0.52)$ and $\mathrm{B}(0.46)$ indicating simultaneous stormtime increases.

(b) $\mathrm{AU}$ with $\mathrm{AL}(-0.62)$ and $A E(0.85), A L$ with $A E(-0.94)$, indicating some relationship but not very strong between the two independent parameters $A U$ and $A L$, and arithmetical relationship between $A E$ and $A U$ or $A L(A L=A U$ negative $A L)$. (c) Dst with V(-0.59) (well-known, first indicated by Snyder et al., 1963), $\mathrm{AL}(0.54), \mathrm{AE}(-0.46)$, but not with $\mathrm{AU}(-0.22)$, indicating that equatorial Dst current variations may have some similarity with the westward auroral electrojet AL but almost none with the eastward auroral electrojet $\mathrm{AU}$.

\section{PLOTS FOR OTHER EVENTS DURING 1982-2003}

Figure 2 shows plots of hourly values of $N, V, B, B z, A U, A L, A E$ and Dst for the event of July 13-14, 1982 in the left half. The interplanetary data are intermittent, but, in conjunction with $A U, A L$, AE and Dst, the storm seems to have started at about 1600 UT of July 13 (marked by a vertical dashed line). Since the Bz data are intermittent, matching with geomagnetic indices is uncertain.

Table 1 - Inter-correlations of the hourly values of interplanetary N, V, B, Bz, auroral AU, AL, AE, and Dst during Apr. 11-14, 1981 (standard error about \pm 0.08 ).

\begin{tabular}{|c|c|c|c|c|c|c|c|}
\hline & $\mathrm{N}$ & $\mathrm{V}$ & $\mathrm{B}$ & $\mathrm{Bz}$ & $\mathrm{AU}$ & $\mathrm{AL}$ & $\mathrm{AE}$ \\
\hline $\mathrm{V}$ & 0.52 & & & & & & \\
\hline $\mathrm{B}$ & 0.46 & 0.17 & & & & & \\
\hline $\mathrm{Bz}$ & -0.13 & -0.22 & -0.17 & & & & \\
\hline $\mathrm{AU}$ & 0.39 & 0.29 & 0.12 & -0.20 & & & \\
\hline $\mathrm{AL}$ & -0.21 & -0.40 & -0.01 & 0.18 & -0.62 & & \\
\hline $\mathrm{AE}$ & 0.30 & 0.39 & 0.06 & -0.20 & 0.85 & -0.94 & \\
\hline Dst & -0.03 & -0.59 & 0.21 & 0.38 & -0.22 & 0.54 & -0.46 \\
\hline
\end{tabular}

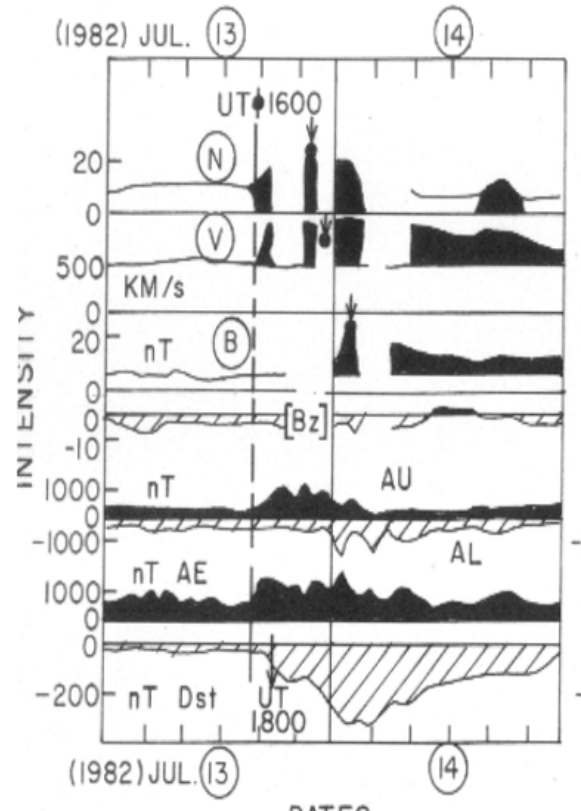

DATES

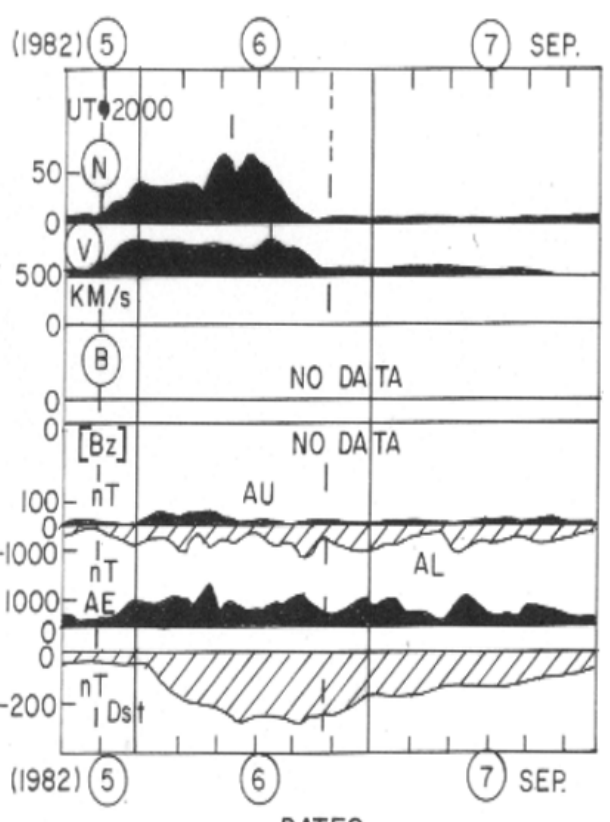

DATES

Figure 2 - Plots of hourly values of N, V, B, Bz, AU, AL, AE and Dst for the event of July 13-14, 1982 in the left half and Sept. 5-7, 1982 in the right half. Positive values are painted black and negative values are shown hatched. 
The Dst negative values started at about 1800 UT, about two hours later than $A U, A L, A E$, and reached a maximum value of $-325 \mathrm{nT}$. The AU values showed maxima several hours earlier than AL This is different from what is mentioned for substorms, namely, the peak time of AU usually occurs several tens of minutes behind the AL peak time which signals the maximum epoch of substorms (Kamide \& Fukushima, 1972). Thus, long-term variations (hours) of $\mathrm{AU}$ and $\mathrm{AL}$ have a different relationship as compared to those of short-term variations (tens of minutes). Part of the discrepancies could be because of the two factors mentioned by Rostoker (2002). Firstly, AU and AL are average values from a number of stations and the absence of data from some vital stations under the electrojet centers could make a difference (even up to $\pm 50 \%$ ) in the magnitude estimates. Secondly, the electrojet centers move with time (e.g., pole ward movement) during the different storm phases (expansion phase, etc.). But, in general, it seems that $\mathrm{AU}$ and $\mathrm{AL}$ do develop partly independently, with incoming solar wind particles hitting different latitudes and longitude differently at different times.

The right half of Figure 2 shows the plots for Sept. 5-7, 1982. There are no data for interplanetary magnetic field. The $\mathrm{N}$ and $\checkmark$ plots indicate a storm commencement at about 2000 UT of Sept. 5 (marked by a vertical dashed line). Again, auroral activities started at about this time, but the Dst variations started a few hours later, at about 2400 UT, and reached a maximum value of $-289 \mathrm{nT}$. The $\mathrm{N}$ and $\mathrm{V}$ abnormal variations ended at about 2000 UT of Sept. 6, but the auroral and Dst variations continued well into Sept. 7. Since magnetic field data are missing, it is not possible to check whether the $B$ component continued to be large on Sept. 7 also. In general, B values returning to normal would indicate that the Earth has come out of the interplanetary blob.

Figure 3 left half shows the plots for Feb. 7-9, 1986. The interplanetary data are intermittent. The auroral indices and Dst storms started at about 1200 UT of Feb. 7 (beginning of the plots), had a slight recovery, and then had another swing at about 2400 UT, at the date line of Feb. 7-8, to reach a maximum Dst value of $-307 \mathrm{nT}$. The positive $A U$ values were much smaller than the negative $A L$ values, so that $A E$ values are roughly the same (sign changed) as the AL values.

The right half of Figure 3 shows the plots for Apr. 10-11, 1990. The interplanetary data were unsatisfactory. The auroral indices show a storm beginning at about 0000 UT of Apr. 10 (beginning of the plots), while the Dst storm strengthened at about 0400 UT (four hours later), and reached a maximum value of $-281 \mathrm{nT}$. Here again, AU values were much smaller than AL values, which had many peaks, unlike the Dst which was smooth. Since magnetic field data are intermittent, the association of these peaks with $\mathrm{Bz}$ changes cannot be checked.

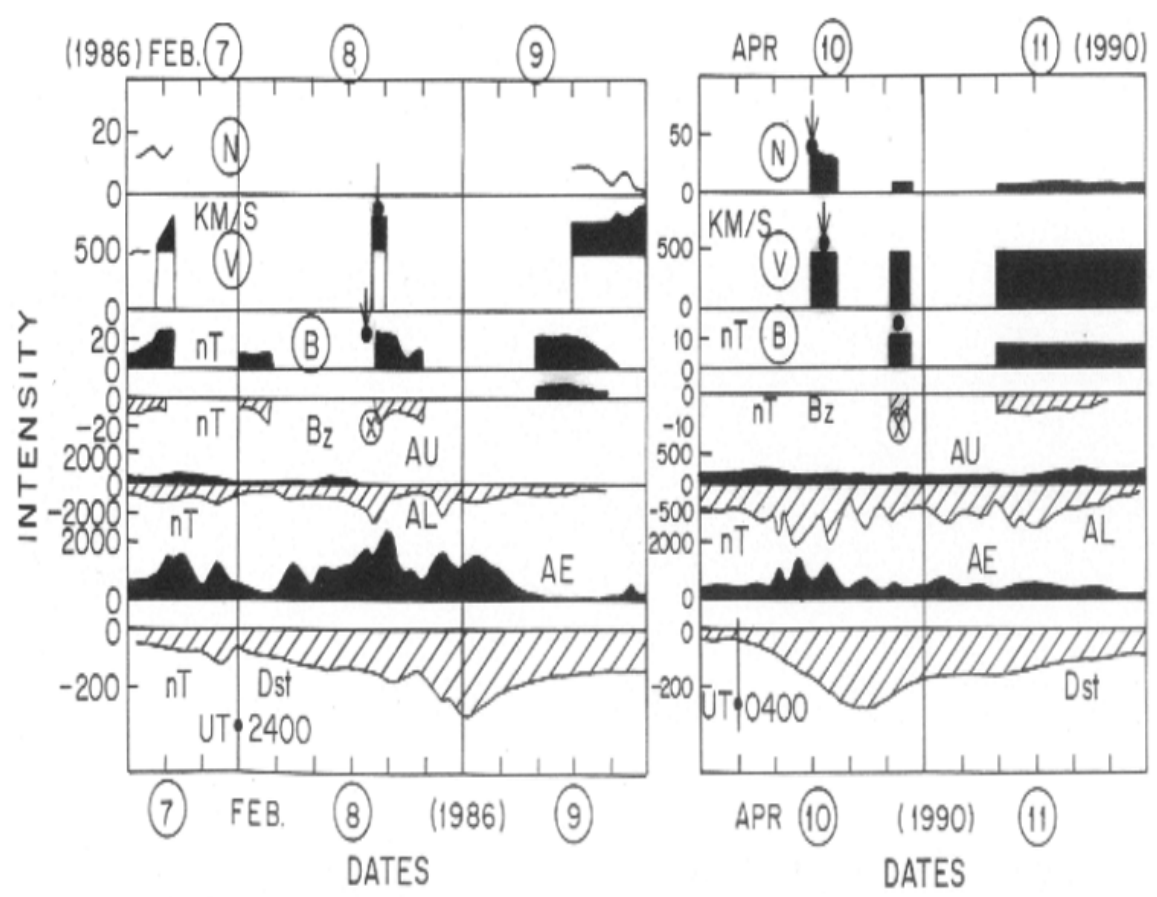

Figure 3 - Plots of hourly values for Feb. 7-9, 1986 (left half) and for Apr. 10-11, 1990 (right half). 

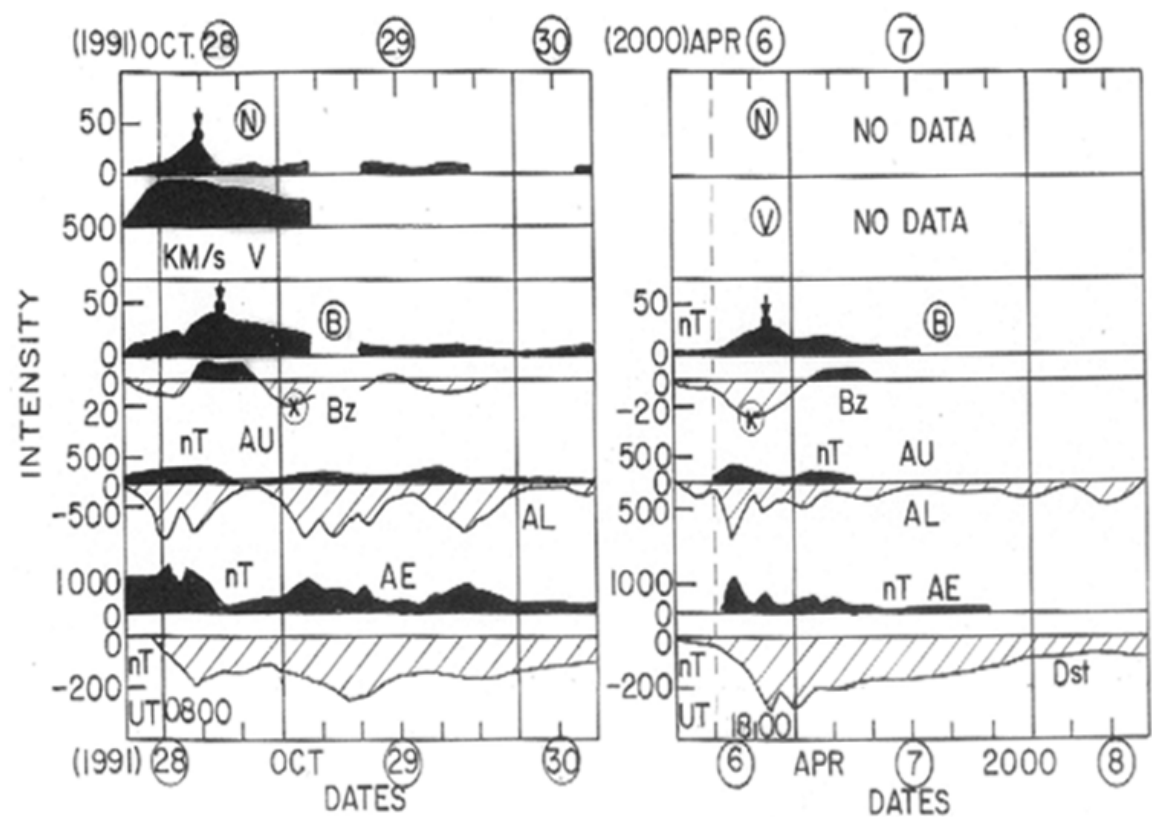

Figure 4 - Plots of hourly values for Oct. 28-30, 1991 (left half) and for Apr. 6-8, 2000 (right half).

Figure 4 left half shows the plots for Oct. 28-30, 1991. Interplanetary data were satisfactory at least in the early part and show a storm beginning at about 0800 UT of Oct. 28 (beginning of the plots). Auroral indices increased at about the same time, while Dst started at about 1200 UT (four hours later) and reached a maximum value of $-254 \mathrm{nT}$. Bz had three swings which were reflected in $\mathrm{AL}$ and Dst (AU values were much smaller than $\mathrm{AL}$ values). Thus, the geomagnetic indices ran parallel to $\mathrm{Bz}$ changes. It is interesting to note that the third swing of Bz was smaller $(-10 \mathrm{nT})$ than the second swing $(-20 \mathrm{nT})$, but the AL values were comparable.

The right half of Figure 4 shows the plots for Apr. 6-8, 2000. The interplanetary data were missing for $\mathrm{N}, \mathrm{V}$ but existed for $\mathrm{B}$, Bz. The storm started at about 1800 UT of Apr. 6 (marked by a vertical dashed line), for all indices (an example of synchronization). Dst reached a maximum value of $-268 \mathrm{nT}$. Coinciding with the large Bz negative. Here again, AU values were much smaller than $A L$ values, which had many peaks, continuing even when $B z$ fluctuations had stopped and B values had come to normal. Thus, $A L$ values had fluctuations even after the storm ceased.

Figure 5 shows plots for six events, (a) Jul. 15-17, 2000, (b) Mar. 30-31, 2001, (c) Apr. 11-12, 2001, (d) Nov. 5-7, 2001, (e) Oct. 29-30, 2003, (f) Nov. 20-21, 2003.

In (a) Jul. 15-17, 2000, interplanetary data were intermittent, auroral indices increased from about 1200 UT of July 15 (begin- ning of the plots), while Dst started at about 1800 UT (six hours later) and reached a maximum value of -301 . Interplanetary data were intermittent, auroral indices increased from about 1200 UT of July 15 (beginning of the plots), while Dst started at about 1800 UT (six hours later) and reached a maximum value of -301 . No magnetic data were available for comparison, but AU values were as large as AL values.

In (b) Mar. 30-31, 2001, interplanetary data were satisfactory, the storm started at 2000 UT on Mar. 30 in all indices (marked by a vertical dashed line), except Dst, for which the storm started at about 0400 UT of March 31 (eight hours later, marked by a vertical dashed line), and reached a maximum value of $-358 \mathrm{nT}$. The Bz had two major swings of more than $-25 \mathrm{nT}$, but $\mathrm{B}$ had four swings, AU had four, and AL had more than four. Thus, AL seems to have some swings even when Bz was not negative.

In (c) Apr. 11-12, 2001, interplanetary data were satisfactory, the storm started at 1200 UT on Apr. 11 in all indices (marked by a vertical dashed line), except Dst, for which the storm started at about 1600 UT of Apr. 11 (four hours later, marked by a vertical dashed line), and reached a maximum value of $-256 \mathrm{nT}$. The $\mathrm{Bz}$ had two swings, AU had two, but AL had three. Thus again, AL seems to have some swings even when Bz was not negative.

In (d) Nov. 5-7, 2001, interplanetary data were missing, the storm started at 2000 UT on Nov. 5 in all indices including Dst (marked by a vertical dashed line), for which the storm reached a 

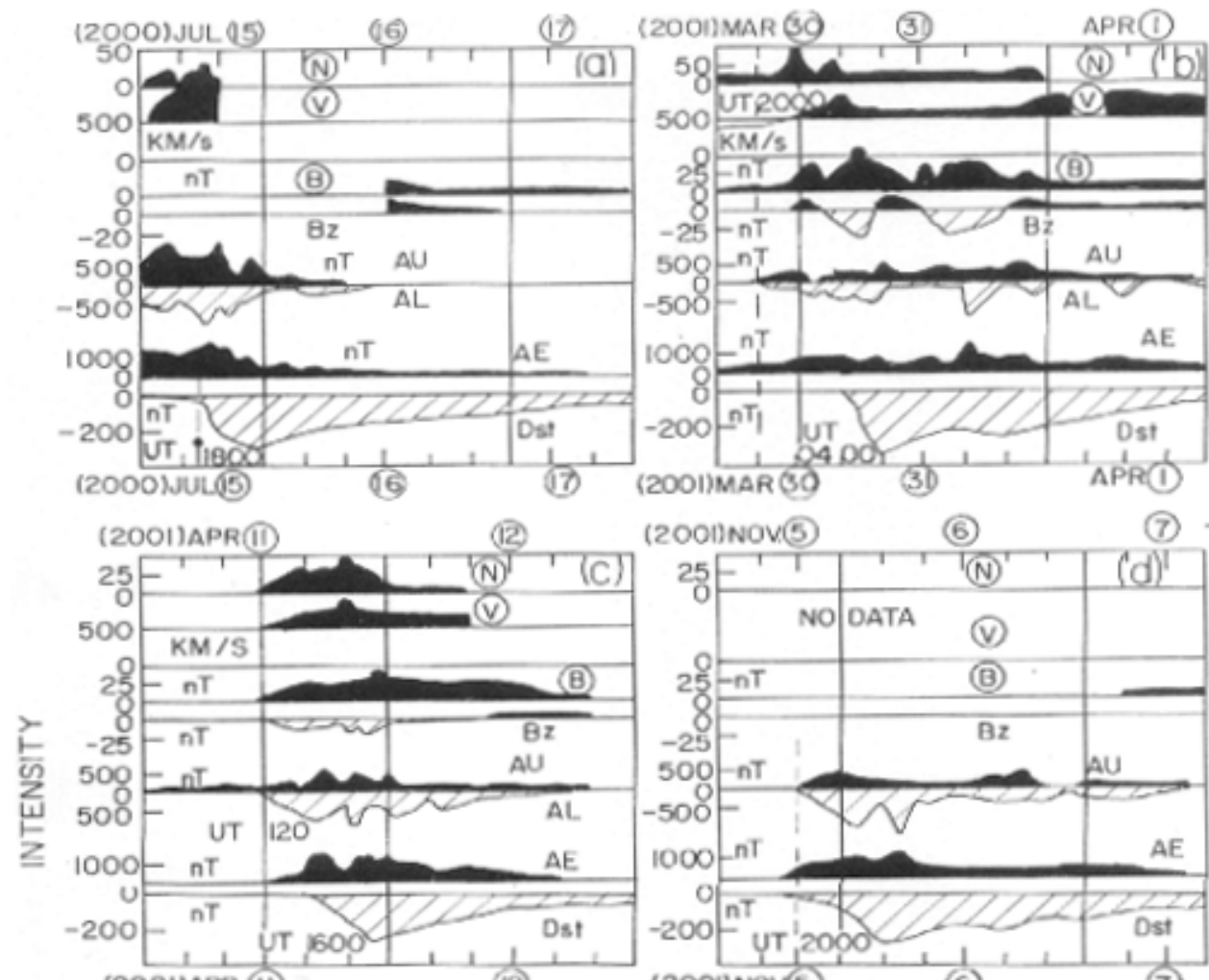

(5OOnNov(5)

(6)

(7)

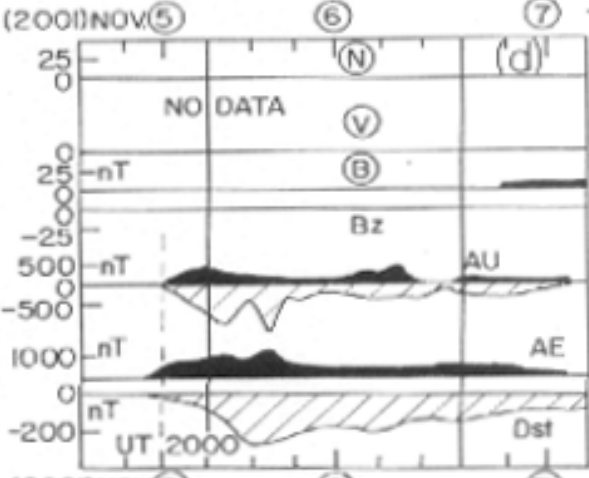

$$
\text { (2OOI)APR (II) }
$$
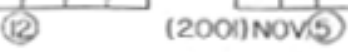

(6)

(7)

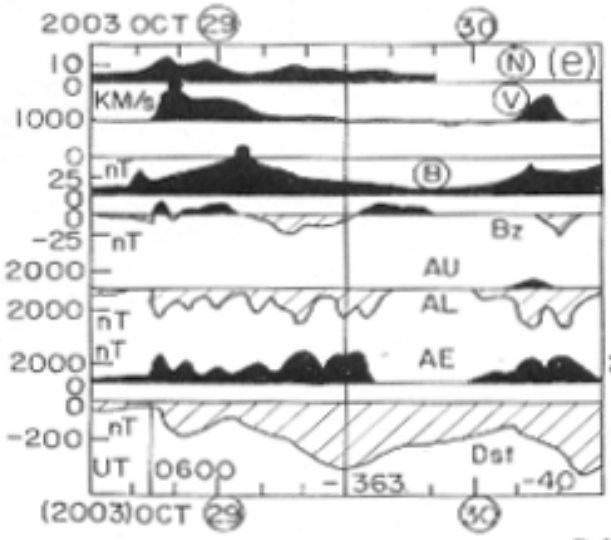

\section{DATES}

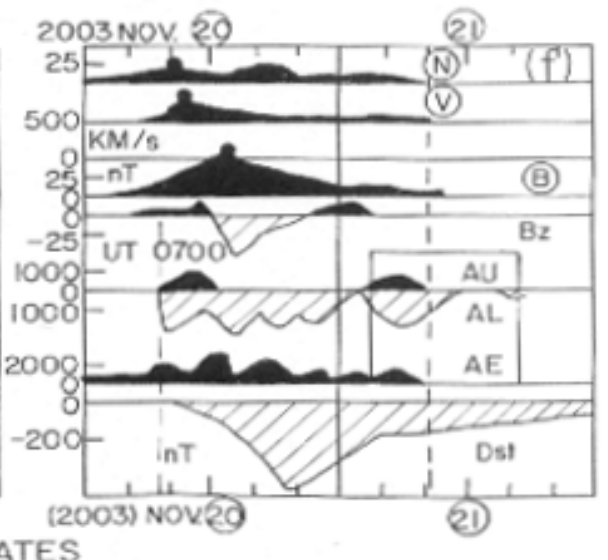

Figure 5 - Plots of hourly values for (a) July 15-17, 2000; (b) Mar. 30-31, Apr. 1, 2001; (c) Apr. 11-12, 2001; (d) Nov. 5-7, 2001; (e) Oct. 29-30, 2003; (f) Nov. 20-21, 2003.

maximum value of $-277 \mathrm{nT}$. The Bz values were not available, but AU had two swings and AL had three.

The (e) and (f) plots are for the famous Halloween events of October-November 2003. (In the WDC for Geomagnetism, Kyoto website, hourly values in digital form are available only up to 2001. For 2002 onwards, only plots are available. Hence, the plots in (e) and (f) are quantitatively approximate). In (e) Oct.
29-30, 2003, N data were missing in some instruments or unreliable in some others (SWEAM data, Skoug et al., 2004). However, PWI (plasma wave) instrument on Geotail gave some data (Toshio Terasawa, website http://www-space.eps.s.u-tokyo.ac.jp/ terasawa/200310/). These have been plotted for N. The V data also had problems but approximate values are plotted, for $B$ and Bz data also (Skoug et al., 2004). This storm was one of the 
extremely high speed storms (V exceeded $2000 \mathrm{~km} / \mathrm{s}$ ) and seems to have started at about 0600 UT of Oct. 29 in all indices including Dst (marked by a vertical dashed line), for which the storm reached a maximum value of $-363 \mathrm{nT}$ in a first swing at 2400 UT of Oct. 29, and -401 nT in a second swing at 2200 UT of Oct. 30, both these well matched with similar Bz negative swings. The AU and AL had a very complex structure. AU was very small as compared to AL, which had many peaks besides two peaks matching with the Bz peaks. Thus, AL had some peaks unrelated to $\mathrm{Bz}$ changes. The $\mathrm{B}$ values had two major peaks, first at about 1600 UT of Oct. 29 and the second at about 16002000 UT of Oct. 30. Thus, this was an interval of two successive interplanetary structures (blobs) separated by about 24-28 hours. Large negative Bz occurred at about 2000 UT on Oct. 29 and 2000 UT on Oct. 30. These caused corresponding Dst main phases. However, in the auroral indices, AU was very small, $\mathrm{AL}$ and AE had enormous values (exceeding $2000 \mathrm{nT}$ ) and had major peaks matching with the negative Bz excursions but also had other peaks in between.

In (f) Nov. 20-21, 2003, interplanetary data were available fully. The $V$ values were moderate and rose from a base value of $\sim 500 \mathrm{~km} / \mathrm{s}$ at about $0700 \mathrm{UT}$ of Nov. 20 (starting of the storm, marked by a vertical dashed line) to values of only about $800 \mathrm{~km} / \mathrm{s}$. This was a simple but strong storm with Dst rea- ching a very high value of $-470 \mathrm{nT}$. B and Bz had one strong swing, but AU, AL and AE had many peaks. Particularly intriguing is the abnormal increases in $\mathrm{AU}, \mathrm{AL}, \mathrm{AE}$ during 04000800 UT on Nov. 21 (marked in a square) which have no corresponding changes in interplanetary parameters (the Earth had come out of the blob).

Table 2 lists the storm dates and the maximum values of the various indices during the various storms (numbered 1-13, values for 12 and 13 are approximate). The Dst storms were chosen as severe (exceeding $250 \mathrm{nT}$ ) and the highest value is $-470 \mathrm{nT}$. Table 3 shows the inter-correlations of the maximum values of Table 2. Table 4 shows the inter-correlations for the geomagnetic indices Dst, $A E, A U, A L$ calculated from the hourly values in each storm separately. The following may be noted in Tables 2 , 3 and 4 :

(1) Dst has a poor correlation $(-0.30)$ with interplanetary V. A good correlation was reported first by Snyder et al. (1963), but subsequent analyses have shown that with only $V$, the correlations are poor. The most glaring discrepancy was observed during the Halloween events. On Oct. 29, 2003 , the V value was very large $(2200 \mathrm{~km} / \mathrm{s})$, almost 3 times that of Nov. 20, $2003(700 \mathrm{~km} / \mathrm{s})$, but the Dst values in the two storms were almost equal (-401 and $-470 \mathrm{nT}$ ). The reason is that negative Bz plays a much more impor-

Table 2 - Maximum values of Dst, N, V, B, Bz, AU, AL, AE during thirteen severe geomagnetic storms.

\begin{tabular}{|c|c|c|c|c|c|c|c|c|c|}
\hline Number & $\begin{array}{c}\text { Event } \\
\text { Date }\end{array}$ & $\begin{array}{c}\text { Dst } \\
\mathrm{nT}\end{array}$ & $\begin{array}{c}\mathrm{N} \\
/ \mathrm{cm}^{3}\end{array}$ & $\begin{array}{c}\mathrm{V} \\
\mathrm{km} / \mathrm{s}\end{array}$ & $\begin{array}{c}\mathrm{B} \\
\mathrm{nT}\end{array}$ & $\begin{array}{c}\mathrm{Bz} \\
\mathrm{nT}\end{array}$ & $\begin{array}{c}\mathrm{AU} \\
\mathrm{nT}\end{array}$ & $\begin{array}{c}\mathrm{AL} \\
\mathrm{nT}\end{array}$ & $\begin{array}{c}\mathrm{AE} \\
\mathrm{nT}\end{array}$ \\
\hline 1 & $13 / 04 / 81$ & -311 & 68 & 669 & 30.1 & -25.5 & 479 & -648 & 1235 \\
\hline 2 & $14 / 07 / 82$ & -325 & 27 & 986 & 22 & -9.6 & 1227 & -1614 & 1877 \\
\hline 3 & $06 / 09 / 82$ & -289 & 70 & 874 & & & 698 & -1163 & 1590 \\
\hline 4 & $09 / 02 / 86$ & -307 & & 898 & 25.2 & -18.8 & 499 & -2739 & 2503 \\
\hline 5 & $10 / 04 / 90$ & -281 & 36 & 491 & 10.3 & -8.6 & 600 & -1424 & 1555 \\
\hline 6 & $29 / 10 / 91$ & -254 & 41 & 994 & 40.5 & -16.8 & 389 & -1386 & 1731 \\
\hline 7 & $06 / 04 / 00$ & -288 & & & 30.3 & -27.5 & 371 & -1188 & 1559 \\
\hline 8 & $15 / 07 / 00$ & -301 & 25 & 1040 & & & 1075 & -1059 & 1897 \\
\hline 9 & $31 / 03 / 01$ & -358 & 102 & 726 & 46.8 & -44.9 & 430 & -1375 & 1486 \\
\hline 10 & $11 / 04 / 01$ & -256 & 34 & 746 & 33.1 & -20.8 & 670 & -1119 & 1375 \\
\hline 11 & $06 / 11 / 01$ & -277 & & & & & 584 & -1553 & 1627 \\
\hline 12 & $29 / 10 / 03$ & -401 & & 2200 & 47.2 & -29.2 & 1000 & -3500 & 3500 \\
\hline 13 & $20 / 11 / 03$ & -470 & 22 & 700 & 55.8 & -45.6 & 600 & -2000 & 2000 \\
\hline & Mean & -316 & 47 & 938 & 34.13 & -24.73 & 663 & -1597 & 1841 \\
\hline & Std. Dev & 61 & 26 & 449 & 13.61 & 12.79 & 272 & 763 & 592 \\
\hline & $\%$ Std.Dev & -19 & 57 & 48 & 40 & -52 & 41 & -48 & 32 \\
\hline
\end{tabular}


Table 3 - Inter-correlations of the maximum values in thirteen storm events.

\begin{tabular}{|c|c|c|c|c|c|c|c|c|}
\hline & Dst & $\mathrm{N}$ & $\mathrm{V}$ & $\mathrm{B}$ & $\mathrm{Bz}$ & $\mathrm{VBz}$ & $\mathrm{AU}$ & $\mathrm{AL}$ \\
\hline $\mathrm{N}$ & 0.04 & & & & & & & \\
\hline $\mathrm{V}$ & -0.30 & -0.22 & & & & & & \\
\hline $\mathrm{B}$ & -0.67 & 0.21 & 0.36 & & & & & \\
\hline $\mathrm{Bz}$ & 0.71 & -0.45 & -0.06 & -0.85 & & & & \\
\hline $\mathrm{VBz}$ & 0.66 & -0.44 & -0.81 & -0.73 & 0.61 & & & \\
\hline $\mathrm{AU}$ & -0.20 & -0.52 & 0.49 & -0.11 & 0.31 & -0.21 & & \\
\hline $\mathrm{AL}$ & 0.52 & 0.38 & -0.73 & -0.28 & 0.10 & 0.69 & -0.25 & \\
\hline $\mathrm{AE}$ & -0.49 & -0.61 & 0.87 & 0.30 & -0.07 & -0.74 & 0.42 & -0.95 \\
\hline
\end{tabular}

Table 4 - Inter-correlations of the hourly values of the geomagnetic indices Dst, AE, AU, AL separately for each of the eleven storms in 1981-2001.

\begin{tabular}{|c|c|c|c|c|c|c|c|}
\hline \multirow{2}{*}{ Event No. } & \multirow{2}{*}{ Interval } & \multicolumn{7}{|c|}{ Correlations } \\
\cline { 3 - 8 } & & Dst vs. AE & Dst vs. AU & Dst vs. AL & AE vs. AU & AE vs. AL & AU vs. AL \\
\hline 1 & Apr. 11-13, 1981 & -0.46 & -0.22 & 0.54 & 0.85 & -0.94 & -0.62 \\
\hline 2 & Jul. 13-14, 1982 & -0.41 & 0.08 & 0.62 & 0.66 & -0.60 & 0.20 \\
\hline 3 & Sep. 5-7, 1982 & -0.40 & 0.21 & 0.57 & 0.47 & -0.87 & 0.04 \\
\hline 4 & Feb. 7-9, 1986 & -0.31 & 0.26 & 0.36 & -0.04 & -0.96 & 0.31 \\
\hline 5 & Apr. 10-11, 1990 & -0.11 & 0.31 & 0.27 & -0.02 & -0.93 & 0.32 \\
\hline 6 & Oct. 28-30, 1991 & -0.30 & 0.05 & 0.38 & 0.74 & -0.98 & -0.57 \\
\hline 7 & Apr. 6-8, 2000 & -0.17 & -0.15 & 0.16 & 0.82 & -0.97 & -0.67 \\
\hline 8 & July 15-17, 2000 & 0.07 & -0.03 & -0.18 & 0.97 & -0.96 & -0.86 \\
\hline 9 & Mar. 30-Apr. 1, 2001 & 0.03 & 0.13 & 0.02 & 0.65 & -0.94 & -0.36 \\
\hline 10 & Apr. 11-12, 2001 & -0.50 & -0.12 & 0.61 & 0.78 & -0.94 & -0.52 \\
\hline 11 & Nov. 5-7, 2001 & -0.50 & -0.02 & 0.60 & 0.60 & -0.92 & -0.24 \\
\hline & Maximum & 0.07 & 0.31 & 0.62 & 0.97 & -0.60 & 0.32 \\
\hline & Minimum & -0.50 & -0.22 & -0.18 & -0.04 & -0.98 & -0.86 \\
\hline
\end{tabular}

tant role than V (Gonzalez et al., 1994), with correlations of Dst versus $\mathrm{B}(-0.67)$, versus $\mathrm{Bz}(0.71)$ and versus the product VBz (0.66).

(2) Dst has a poor correlation with AU (-0.20) but has better (moderate) correlations with $\mathrm{AL}(0.52)$ and $\mathrm{AE}(-0.49)$, indicating that eastward auroral electrojet $\mathrm{AU}$ is more or less independent of Dst, while the westward auroral electrojet AL may have at least a partial relation with Dst. On the other hand, interplanetary $\mathrm{N}$ (number density) has a better, though moderate, correlation with $\mathrm{AU}(-0.52)$ and $\mathrm{AE}$ $(-0.61)$ at least in this case.

(3) V has a good correlation with $\mathrm{AL}(-0.73)$.

(4) AU has a poor correlation with AL $(-0.25)$. Thus the eastward and westward auroral electrojets evolve almost independently of each other. The mean value of the ratio AU/AL is $-0.48( \pm 0.25)$. Thus, the auroral eastward electrojet $\mathrm{AU}$ is about $1 / 5^{\text {th }}$ to $3 / 4^{\text {th }}$ of the westward electrojet $\mathrm{AL}$ in strength.

(5) In Table 4, correlations of Dst with AE, AU and AL indices vary widely from event to event $(+0.07$ to -0.50 for Dst vs $A E ;+0.31$ to -0.22 for Dst vs $A U ;+0.62$ to -0.18 for Dst vs $A L)$, indicating very loose and uncertain relationship between the equatorial index Dst and the auroral induces $A E, A U, A L$. Some high correlations are between $A E$ and $A U$ and $A E$ and $A L$, but these are trivial as $A E$ is obtained as AU-AL. Correlations between $\mathrm{AU}$ and $\mathrm{AL}$ are also highly variable $(+0.32$ to -0.86$)$, indicating varying contributions of incoming radiation to the eastward and westward auroral electrojet systems from storm to storm. 


\section{SPECTRUM ANALYSIS}

The AU and AL plots show considerable fluctuations during the storm intervals, with many peaks, some coinciding with negative Bz excursions, others not coinciding. To obtain quantitative estimates of the spectral characteristics during storms, the series of AU and AL series in each storm were subjected to spectral analysis by MEM (Maximum Entropy Method, Burg, 1967; Ulrych \& Bishop, 1975), which locates peaks much more accurately than the conventional BT (Blackman \& Tukey, 1958) method. However, the amplitude (Power) estimates in MEM are not very reliable (Kane, 1977, 1979; Kane \& Trivedi, 1982). Hence, MEM was used only for detecting all the possible peaks $T_{k}(k=1$ to $n)$, using LPEF (Length of the Prediction Error Filter) as 50\% of the data length. These $T_{k}$ were then used in the expression:

$$
\begin{aligned}
f(t) & =A_{0}+\sum_{k-1}^{n}\left[a_{k} \sin \left(2 \pi t / T_{k}\right)+b_{k} \cos \left(2 \pi t / T_{k}\right)\right]+E \\
& =A_{0}+\sum_{k=1}^{n} r_{k} \sin \left(2 \pi t / T_{k}+\phi_{k}\right)+E
\end{aligned}
$$

where $f(t)$ is the observed series and $E$ the error factor. A Multiple Regression Analysis (MRA, Bevington, 1969) was then carried out to estimate $A_{o}\left(a_{k} \cdot b_{k}\right)$, and their standard errors (by a least-square fit). From these, amplitudes $r_{k}$ and their standard error $\sigma_{k}$ (common for all $r_{k}$ in this methodology, which assumes white noise) were calculated. Any $r_{k}$ exceeding $2 \sigma$ is significant at a $95 \%$ (a priori) confidence level.

Figure 6 shows the spectra (amplitudes versus the periodicities found significant), for the storms numbered 1-13, for AU series in the left half, and AL series in the right half. The hatched area in each spectrum is the $2 \sigma$ limit, and lines protruding above this area represent periodicities significant at a better than $95 \%$ confidence level. The amplitudes of significant periodicities are, in general smaller for $\mathrm{AU}$ than for AL. Periodicities for $\mathrm{AU}$ and AL are not the same, and there is bunching around 2-4 hours, 6 hours, and 8-9 hours. A physical explanation for these needs to be explored. The larger periodicities (6-9 hours) may be indicative of long-term changes like latitudinal movements during different phases of the storm.

\section{SHORT-TERM FLUCTUATIONS}

So far, only hourly data were considered. In substorms, fluctuations lasting for a few minutes to tens of minutes have been reported earlier (Nishida, 1971). Here, the event in Figure 5(b) was selected for a finer study. Figure 7 shows plots of 4-minute values for interplanetary B, Bz and terrestrial AU, AL, AE, Dst indices (for Dst, hourly values only) during 0-18 UT of March 31, 2001.
Positive values are painted black and negative values are shown hatched. The B component started increasing at about 0020 UT (vertical dashed line), heralding a storm commencement. The Bz component started as positive and became negative only about 100 minutes later, from 0200 UT in an intermittent way up to $0340 \mathrm{UT}$, then was consistently large negative for the next four hours (up to about $0740 \mathrm{UT}$ ), positive or almost zero for the next six hours (up to 1400 UT), turning thereafter again to negative values up to the end of the plot. Changes of the AU index were small, and the AL index (negative values only) showed large increases, first at about 0040 UT when Bz was positive, then at 0240 UT when Bz was alternating between negative and positive, and further from 0340 UT onwards for several hours when Bz was consistently negative. Later on, AL was large from 1240 UT onwards when Bz was positive. From 1400 UT, Bz was negative and AL was large, but at 1600 UT when Bz was negative, AL increased enormously for almost 80 minutes. The horizontal rectangles below the Bz plot indicate the coincidence (full rectangles) or anti-coincidence (hatched rectangles) of negative Bz with large AL values. The bottom plot is for Dst (hourly values) and shows a strong storm from 0400 UT only, four hours later than B and auroral indices, and showing a smooth recovery from 0600 UT onwards. Interestingly, substorms lasting a few tens of minutes are often mentioned, but in the present case, these seem to be missing in $\mathrm{Bz}$, and seem to be present in $A L$ and $A E$, with successive peak separations of 40-160 minutes (indicated by numbers).

\section{CONCLUSIONS AND DISCUSSION}

The evolutions of the geomagnetic Dst and auroral indices AU, AL, $A E$ were examined in relation to interplanetary parameters for thirteen severe storms (Dst change exceeding $250 \mathrm{nT}$ ) during 19802003. The following was noted:

(1) When the Earth is engulfed by abnormal interplanetary structures, characterized by sudden increases in number density $\mathrm{N}$ and/or solar wind speed $\mathrm{V}$ and/or total magnetic field B, geomagnetic storms may occur, indicated by increases of the geomagnetic disturbance indices Kp, Ap, Dst, AU, AL etc.

(2) Dst changes are very well related to the negative $\mathrm{Bz}$ component of interplanetary magnetic field $B$. At the first sign of Bz turning sufficiently negative (threshold about $5 \mathrm{nT}$ ), Dst shows a smooth main phase decrease within a few hours, followed by a slow smooth recovery during the next few tens of hours. If another negative excursion of Bz occurs 


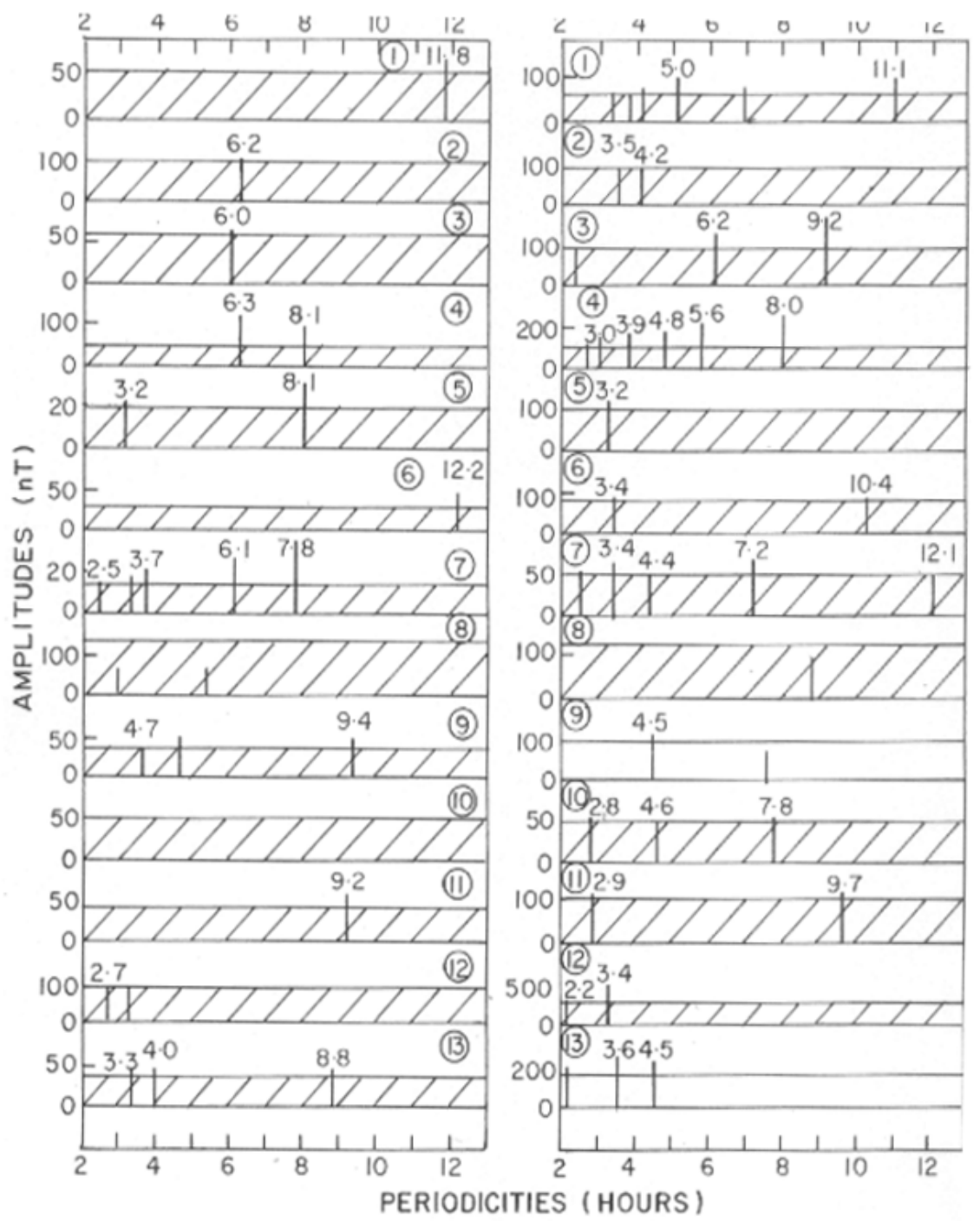

Figure 6 - Spectra (amplitudes versus the periodicities found significant), for the storms numbered 1-13, for AU series in the left half and AL series in the right half. The hatched area in each spectrum is the $2 \sigma$ limit, and lines protruding above this area represent periodicities significant at a better than $95 \%$ confidence level.

in between, Dst shows either a fresh kink (restart of another main phase), or a slowing down of the earlier recovery.

(3) Among the auroral indices, changes in AU (representing an eastward auroral electrojet) are generally smaller than changes in AL (representing a westward auroral electrojet). We do not know how meaningful (or meaningless) AE should be considered, but AE is mostly similar (reversed sign) to AL. Generally, both AU and AL start increasing almost simultaneously with increases of interplanetary magnetic field B, even though Bz may not have turned negative. Hence AU and AL changes may precede Dst changes by a few hours and could have a prediction potential.
(4) $\mathrm{AU}$ and $\mathrm{AL}$ changes are not related to each other; their inter-correlation could be near zero. Whenever Bz is negative, $A L$ indices are invariably high, but the reverse is not true. Large AL changes can occur even when Bz may not be negative, or may be even positive.

(5) In contrast to Dst which has a smooth evolution, AL values show many peaks during the storm and not all these seem to be related to Bz changes. Successive peak separations have a wide range of 40-160 minutes. Spectral analysis of hourly values shows frequent periodicities around 2-4 hours, 6 hours, and 8-9 hours. 


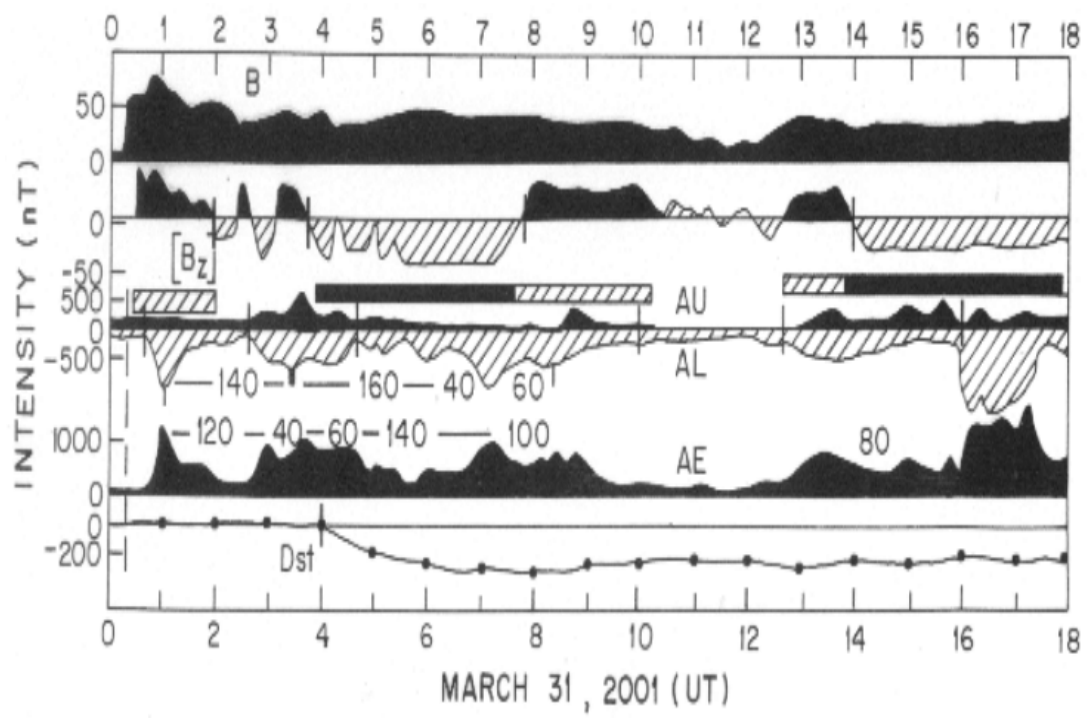

Figure 7 - Plots of 4-minute values for interplanetary B, Bz and terrestrial AU, AL, AE, and hourly values for Dst during 0-18 UT of March 31, 2001. Positive values are painted black and negative values are shown hatched. Numbers on the AL and AE plots indicate separation in minutes between successive peaks.

It seems therefore, that the entry of low energy solar wind particles in the polar regions of the Earth is a complicated process, not completely dominated by the negative Bz valve. Quiet time auroras are always present, though these intensify during storms, and $\mathrm{AL}$ changes can be large even when $\mathrm{Bz}$ is positive. Charged particle precipitation in the auroral region is preferably along magnetic field lines (field-aligned currents) and acceleration processes are involved (Axford \& Hines, 1961). These processes need more detailed studies (using a variety of data inputs and not relying completely on the auroral indices, Rostoker, 2002), different from those needed for the equatorial ring current causing Dst.

\section{ACKNOWLEDGMENTS}

Thanks are due to Dr. Ruth Skoug, Dr. Qiang Hu and Dr. Toshio Terasawa for sending data and information about the October 29, 2003 event privately. Thanks are due to the various workers and the data suppliers and the WDC for Geomagnetism, Kyoto. Thanks are due to $\mathrm{N}$. Ness of Bartol Research Institute and CDAWeb for some interplanetary data for the October-November $2003 \mathrm{Hal}-$ loween events. This work was partially supported by FNDCT, Brazil, under contract FINEP-537/CT.

\section{REFERENCES}

ALLEN J, SAUER H, FRANK L \& REIFF P. 1989. Effects of the March 1989 solar activity. EOS Trans. AGU, 70: 1479.
AXFORD WI \& HINES C0. 1961. A unifying theory of high-latitude geophysical phenomena and geomagnetic storms. Canad. J. Phys., 39: 1443-1464.

BELAND J. 2004. Hydro-Quebec and geomagnetic storms: Measurement techniques. Effects on transmission network and preventive actions since 1989. Paper COSPAR 04-A-02392, PSW1-0012-04, 35 th COSPAR Assembly, July 19-25, 2004, Paris.

BEVINGTON PR. 1969. Data Reduction and Error Analysis for the Physical Sciences. McGraw-Hill, New York, pp. 164-176.

BIERMANN LF. 1951. Kometenschweife und solare Korpuskularstrahlung. Zeitschrift für Astrophysik, 29: 274-286.

BLACKMAN RB \& TUKEY JW. 1958. The Measurement of Power Spectra Dover, New York, 190 pp.

BURG JP. 1967. Maximum Entropy Spectral Analysis. Paper presented at the $37^{\text {th }}$ Meeting. Society of Exploration Geophysics, Oklahoma City, October.

DAVIS TN \& SUGIURA M. 1966. Auroral electrojet activity index AE and its universal time variations. J. Geophys. Res., 71: 785-801.

DUNGEY JW. 1961. Interplanetary magnetic field and the auroral zones. Phys. Rev. Lett., 6: 47-49.

GOLD T. 1959. Plasma and magnetic fields in the solar system. J. Geophys. Res., 64: 1665-1674.

GONZALEZ WD, JOSELYN JA, KAMIDE Y, KROEHL HW, ROSTOKER G TSURUTANI BT \& VASYLIUNAS VM. 1994. What is a geomagnetic storm? J. Geophys. Res., 99C: 5771-5792. 
HUFBAUER K. 1991. Exploring the Sun: Solar Science since Galileo. The John Hopkins University Press, Baltimore, Maryland, USA. 370 p.

KAMIDE Y \& FUKUSHIMA N. 1972. Positive geomagnetic bays in evening high latitudes and their possible connection with partial ring current. Rep. Ionos. Space Res. Japan, 26: 79-101.

KANE RP. 1977. Power spectrum analysis of solar and geophysical parameters. J. Geomag. Geoelect., 29: 471-495.

KANE RP. 1979. Maximum Entropy Spectral Analysis of some artificial samples. J. Geophys. Res., 84: 965-966.

KANE RP. 2005. How good is the relationship of solar and interplanetary plasma parameters with geomagnetic storms? J. Geophys. Res., 110, A02213, doi:10.1029/2005JA010799.

KANE RP \& TRIVEDI NB. 1982. Comparison of maximum entropy spectral analysis (MESA) and least-square linear prediction (LSLP) methods for some artificial samples. Geophysics, 47: 1731-1736.

NISHIDA A. 1971. DP2 and polar substorm. Planet. Space Sci., 19: 205-221.

PARKER EN. 1958. Suprathermal particle generation in the solar corona. Astrophys. J., 128: 677-685.
PARKER EN. 1959. Extension of the solar corona into interplanetary space. J. Geophys. Res., 64: 1675-1681.

ROSTOKER G. 2002. Why we have not yet solved the substorm problem. In: WINGLEE RM (Ed.). Sixth International Conference on Substorms, pp. 1-8, University of Washington, Seattle.

SKOUG RM, GOSLING J, STEINBERG J, McCOMAS DJ, SMITH CW, NESS NF, HU Q \& BURLAGA LF. 2004. Extremely high speed solar wind: October 29-30, 2003. J. Geophys. Res., 109: A09102, doi:10.1029/2004JA010494.

SNYDER CW, NEUGEBAUER M \& RAO UR. 1963. The solar wind velocity and its correlation with cosmic ray variations and with solar and geomagnetic activity. J. Geophys. Res., 68: 6361-6370.

SUGIURA M. 1964. Hourly values of equatorial Dst for IGY. In: Annals of the International Geophysical Year, vol. 35, Pergamon Press, Oxford. 945-948.

TSURUTANI BT, GONZALEZ WD, LAKHINA GS \& ALEX S. 2003. The extreme magnetic storm of 1-2 September 1859. J. Geophys. Res., 108(A7): 1268, doi: 10.1029/2002JA009504.

ULRYCH TJ \& BISHOP TN. 1975. Maximum Entropy Spectral Analysis and autoregressive decomposition. Rev. Geophys., 13: 183-200.

\section{NOTE ABOUT THE AUTHOR}

Rajaram Purushottam Kane. Born on 12 November 1926 at Damoh, MP, India. M.Sc. Physics in 1946 from Banaras Hindu University, India. Ph.D. in 1953 from Bombay University, India. Visited the Institute of Nuclear Studies at the University of Chicago, USA as a Fulbright Smith-Mundt post-doc fellow during $1953-1954$. From 1955 to 1978, worked as a research fellow and Professor at PRL (Physical Research Laboratory), Ahmedabad, India. Participated actively (Coordinator of Cosmic Ray data in India) in the activities of IGY (International Geophysical Years, 1957-1958). Since 1978, working as a Researcher at INPE (Instituto Nacional de Pesquisas Espaciais), São José dos Campos, SP, Brazil. 